\title{
Ironia i sàtira: l'aparició d'una nova Teodora al tron imperial bizantí
}

\author{
Irony and satire: the appearance of a new Theodore \\ on the Byzantine imperial throne \\ Jordi Redondo \\ (GIRLC, Universitat de València)
}

\begin{abstract}
RESUM
\section{Paraules Clau}

ballarina, devoradora d'homes, etopeia, literatura bizantina, Tirant lo Blanc.
\end{abstract}

El present treball mira de presentar com el personatge de l'anònima emperadriu al Tirant lo Blanc ha estat modelat sota el patró de la tradició literària sobre l'emperadriu bizantina Teodora. La seua etopiea es deu a un autor contemporani, l'historiador Procopi, el qual va conèixer personalment i de molt a prop la vida a palau. El joc intertextual aporta una prova sòlida, en la nostra opinió, sobre la recepció del personatge a partir de la ltradició literària bizantina.

\section{Abstract}

The paper tries to show that the character of the anonymous empress in Tirant lo Blanc was featured with the traits of the literary tradition on the Byzantine empress Theodora. Her ethopoia was constructed by a contemporary of her, the historian Procopius, who knew personally and from a very close position the inner court life. The intertextual play gives solid proof, in our opinion, on the reception of the character from the Byzantine literary tradition.

\section{KEYWORDS}

Dancer, man-eater, ethopoia, Byzantine literature, Tirant lo Blanc.

Rebut: 02/09/2020

Acceptat: $15 / 10 / 2020$ 


\title{
L'emperadriu del Tirant lo Blanc i Teodora, emperadriu bizantina
}

Una obra coral de l'extensió del Tirant lo Blanc dóna lloc a que el(s) seu(s) autor(s) assoleixi(n) un tractament acurat dels principals personatges. Tanmateix, a dia d'avui falten o la monografia que s'ocupi de presentar-nos-els amb l'aprofundiment i l'exigència interpretativa dignes de la novella, o en el seu defecte els estudis parcials que cobreixin, ni que sigui parcialment, el coneixement d'aquesta vessant de l'obra. Aquí dibuixarem, esperem que amb traç prou subtil, els trets que delineen el personatge de l'anònima emperadriu de Bizanci, i d'acord amb el que hem proposat per a altres aspectes del Tirant ho farem a partir dels precedents literaris que es registren a la tradició grega.

El principi del capítol ccccL del Tirant lo Blanc, molt breu, diu el següent:

\begin{abstract}
Llevades les taules, les danses començaren molt grans. Lo rei de Sićlia suplicà a l'Emperadriu que li fes gràcia de dansar ab ell, e la virtuosa senyora li repòs que gran temps havia que deixada se n'era, mas que ho faria per contentar-lo. E dansaren los dos moltes danses, car l'Emperadriu era estada en son temps molt agraciada e dansadora singular. Dansà aprés l'excelsa Princesa $\mathrm{ab}$ Tirant $\mathrm{e} a b$ lo rei de Fes, e lo rei de Sicília dansà $\mathrm{ab}$ l'ínclita reina de Fes. Aprés dansaren tots los altres nobles e cavallers ab les dames.

E la plaça era plena de la popular gent de la ciutat, qui miraven la tan graciosa festa e altres qui ballaven de diversos balls, que era una admirable cosa de veure festa de tanta solemnitat per la molta alegria que tenien de la pau e gloriosa victòria que obtesa havien. E d'altra part, per la ciutat se feien d'altres maneres de solaços de balls e de jocs de gran alegria, per ço com la majestat de l'Emperador havia manat que fos la festa celebrada per huit dies. De matí anaven a l'església, on se feien solemnes professons e oficis; e aprés dinar, danses e gales e coses d'alegria.
\end{abstract}

Els estudiosos no han remarcat res sobre l'allusió a l'emperadriu, la descripció de la qual fa inequívoc el reconeixement d'una figura històrica ben notable: la definició descansa en dues característiques, l'excelsa bellesa i el mestratge en l'art de la dansa. La conjunció de tots dos casos apunta a una única emperadriu bizantina, Teodora. Ens referim a la Teodora més coneguda, dona de Justinià des del $525 \mathrm{i}$ emperadriu des del 527 fins a la seua mort el 548. En realitat l'atenció dels investigadors s'ha centrat en l'affaire amorós de l'emperadriu amb el jove Hipòlit ${ }^{1}$, en què la novel' la s'ocupa molt més abans (capitols CCXLVIII-CCLXIV) i l'episodi central del qual té una impagable anàlisi a Beltran (1989), amb esment especial a la imbricació de motius tant literaris, antics i medievals, com folclòrics, dins la construcció dels personatges i de la trama.

Fou després Cacho Blecua (1993) qui va aprofundir en el personatge de l'emperadriu, que compara amb la malaguanyada Isolda, i amb la no menys dissortada Carmesina (esp. 1993: 156). Però a diferència d'aquestes esforçades amants, destinades a una fi tràgica, l'emperadriu, com molt bé diu Cacho Blecua, no viu pas un amor «més enllà de la mort», ni de bon tros. Aportació significativa del mateix investigador és la indicació de com el personatge de l'emperadriu té el seu model al fabliau, que l'autor de l'obra ha traslladat a la cort de Constantinoble (Cacho Blecua, 1993: 166). I emcara més de prop, a l'exercici d'introspecció del nostre personatge, Alemany reconeix a

1. Es tracta d'un nom parlant que evoca el mite de Fedra, la madrastra que fa per seduir un jove curull d'innocència i que serveix la verge Àrtemis amb tant de passió com odiava la femme fatale que l'assetja, Afrodita. Resulta a aquest respecte programàtica la salutació de l'emperadriu al capítol CCLXII, quan en besar-lo li diu a Hipòlit: «Lo meu fill...». 
la perfecció el caire lasciu de l'emperadriu, l'estratègia amorosa de la qual no guarda cap de parió amb les reticències i els dubtes de Carmesina, tot i l'amor que sent per Tirant (2002: 405-406).

A aquestes pàgines volem, doncs, afegir als models proposats un altre entre la literatura i la historia: el de Teodora. No sabríem precisar fins a quin punt aquesta emperadriu va ésser una esposa infidel, si atenem a la seua trajectòria segons que ens ha arribat documentada (Leppin, 2002). La realitat històrica, tanmateix, no condiciona la realitat literària, a la qual Teodora traeix el seu august espòs. L'enperadriu del Tirant ho fa també, si més no amb Hipòlit, qui precisament a la mort del malaurat emperador pujarà al tron com a legítim espòs de l'augusta.

L'emperadriu Teodora va estar un puntal cabdal del moviment anticalcedonià (Finneran, 2010: 211); les seues activitats varen arribar fin i tot a organitzar maniobres de desestabilització de la política de l'emperador (Finneran 2010: 206). Teodora, en realitat, no va basar el seu èxit en el domini de la dansa. La Història secreta de Procopi mostra amb claredat que Teodora no sabia de ballar, el que no li impedia d'assolir un èxit extraordinari. L'historiador s'estén sobre la personalíssima pràctica de Teodora pel que fa a les arts de seducció obtingudes mitjançant la nuesa i la postura, però no ens la presenta, insistim-hi, com a una destra balladora. A la seua Història secreta, Procopi en diu el següent:

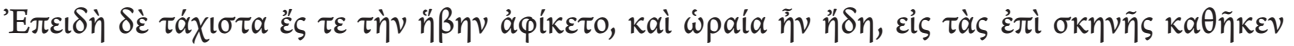

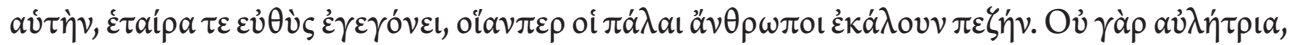

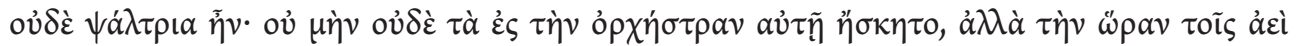

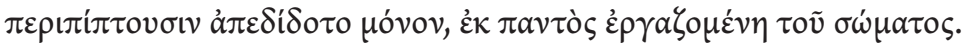

[I el més aviat possible, tan bon punt va arribar a la pubertat, com que ja en tenia l'edat, la va fer prendre lloc entre les que apareixien a escena i esdevenia tot seguit una hetera del tipus que la gent d'abans anomenaven una d'ordinària. No era pas flautista ni menys encara arpista; no tenia tampoc gens de pràctica en les tècniques de la dansa, sinó que només oferia en torna la seua bellesa a aquells que en cada ocasió es trobaven amb ella, que s'hi posava amb tot el seu cos. (Procopi, Història secreta, ix, 4)]

Tanmateix el clixè de la Teodora ballarina encaixava amb un de molt antiga nissaga, el de les dansaires gaditanes que el món romà coneix com a Gaditanae puellae, i que, encara que en principi es dedicaven a ballar, el que practicaven era una potent incitació a l'alliberament sexual. Comptem a aquest respecte amb els testimoniatges de l'historiador Plini el Jove i dels poetes Marcial i Juvenal (Plin. NH i 15 i 41; Mart. v 78, vi 71 i xiv 203, Iuv. Sat. xi 162ss.). La nostra impressió, doncs, és que la pèssima reputació atorgada a Teodora per Procopi i altres historiadors que el seguiren va conduir a la constitució d'una imatge errònia, on el paper de provocadora sexual i de prostituta dins el context dels espectacles circenses va dur els qui en tractaven a considerar-la una ballarina. No tenim el més mínim dubte que la figura d'una emperadriu amb el passat de Teodora va captivar la imaginació de molts autors. També a la nostra época continua obert el debat sobre quins són els límits entre el personatge real i el que la fama ha forjat (Fisher, 1973; Cameron, 1985; Allen, 1992).

Si la Teodora de la Història secreta fou o no una tan àvol persona, empedreïda, rancuniosa i cruel, ens obliga a plantejar-nos els interessos de Procopi per a fer-ne un personatge abominable. De fet, anys enrere, a la Història de les guerres, ens n'havia deixat un retrat inesborrable com a paradigma de governant coratjós, compromès, ple de responsabilitat i de sentit del poder (Evans, 1984). De la Teodora real hi ha molts aspectes que no podem saber amb seguretat, però sí que te- 
nim indicis d'algunes de les seues capacitats ${ }^{2}$. Amb una perspectiva del tot diferent, Ziche (20122013) aprecia al retrat de Teodora una sèrie de clixès històrics i retòrics presents a la tradició del gènere ja des del romà Tàcit; més encara, Procopi no hauria tingut cap raó per a blasmar Teodora ni per la seua condició de dona ni pel seu capteniment. Una nova anàlisi dels models literaris emprats per Procopi, a càrrec de Grau i Febrer, ha assolit una explicació satisfactòria de la construcció del retrat de la Història secreta, bastit a partir de la mixtura de diferents tradicions narratives, des de la invectiva iambogràfica amb arrels a l'època arcaica fins a l'hagiografia contemporània de l'autor (Grau i Febrer, 2020).

Una segona Teodora fou emperadriu segles més endavant, entre els anys 842 i 856 , com a regent després de la mort del seu marit Teòfil, però no hi ha la més minsa possibilitat d’acomparar-la amb la balladora, perquè l'hagiografia res no en diu de dolent; així ho evidencia, per exemple, la

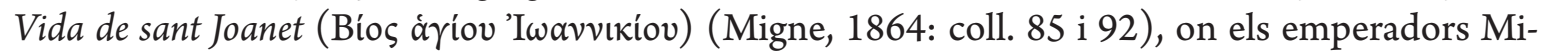
quel II i Teodora són presentats com a restauradors de la fe. És així com neixia la lloada imatge de Teodora (Kotsis, 2016), però una sense cap relació amb l'esposa de Justinià. No hi ha, en canvi, arguments en favor que el personatge d'aquesta emperadriu hagués pogut estar al darrere del de la dona que a la literatura castellana medieval coneixem com La donzella Teodor (Parker, 1996; Porcel Bueno, 2015).

\section{L'emperadriu del Tirant lo Blanc: balladora i depredadora sexual}

Aquesta etopeia de l'emperadriu balladora i sexualment dominant és la que segons nosaltres té una cabdal influència en la creació del personatge del Tirant lo Blanc. La seua aparició es produeix al capítol cXviI, Com Tirant fon arribat en Constantinoble, e les raons que l'Emperador li dix. I tot i que l'autor dóna pas molt aviat els dubtes sobre la naturalesa dels sospirs de la dama ${ }^{3}$, haurem d'esperar encara que passi força temps dins la seqüència narrativa per a conèixer per què pateix l'emperadriu. En tindrem noticia certa quan al capítol ccxx es queixa obertament de la incapacitat física del seu home:

- E fon-se girada devers l'Emperador-: I vós, en beneit, ¿per a què voleu altra muller, per dar-Ii esplanissades e no estocades? Guardau que jamés morí dona ni donzella de joc d'esplanissades (Martorell, 1979: 671).

Algun temps després, ja al capítol CCXLVIII, l’autor expressa sense vacillacions que la dona està inflamada d'amors pel seu desig del jove Hipòlit:

L'Emperadriu tingué presumpció que Hipòlit devia amar, e tota la tristor que la sua cara manifestava no devia altra cosa ésser sinó passió d’amor (Martorell, 1979: 734-735).

El festeig entre Hipòlit i l'emperadriu ens porta també aquesta pregunta, tot just al capítol següent, que probablement amaga més del que diu, potser perquè la ironia del lloador té com a objectiu el contrari del que expressa:

2. A un estudi que només es pot qualificar de meravellós (Scarborough, 2013) ens són oferts testimonis fefaents de com l'habilior d'evitar la concepció era una de les pròpies de les prostitutes bizantines al segle vi d.C., com ho mostra el Tetrabiblon del metge Aeci d'Amida.

3. TlB, cap. CXxvI: «Car jo viu a la sereníssima senyora Emperadriu e l'excelsa Princesa, les dues llà en taula posades, e sentí un fort e profunde sospir que la senyora Emperadriu llançà, pensí que sospirava per aquell que havia parit. En aquell cas la mia ànima, de pietat, sentí dolor inestimable» (Martorell, 1979: 401-402). 
¿Què fall a vostra majestat sinó que portàs diadema de santa e per vós se cantàs Te Deum laudamus e totes les esglésies fessen festa de dotze lliçons, per ço com deveu ésser nomenada per lo món deessa de la terra? (Martorell, 1979: 735).

L'etopeia de la dama va completant-se també amb els seus mateixos raonaments, com ara el següent, al capítol CCLVI, en favor de la satisfacció dels desitjos amorosos a despit de les convencions socials:

- Jo ho volguera, Hipòlit, tu m'haguesses feta certa del que jo et demane, e no deus per res estar de dir-me clarament ta intenció, car amor no accepta noblesa, ni llinatge, ni egualtat, car no fa diferència si és d'alt lloc o de baix (Martorell, 1979: 745).

L'elogi de la bellesa de l'emperadriu la fa aparèixer com una extraordinària dona gairebé inabastable a les obres del temps. Llegim les incomparables paraules que l'autor dedica a la descripció física del personatge, al capítol CCLXII:

E dit açò, Hipòlit prestament fon despullat, anà a la gentil vella e despullà-li la roba que vestia, e restà en camisa. $\mathrm{E}$ tenia la sua noble persona de tanta gentilea e disposició, que coneguera, qui en tal so la ves, com era donzella que posseïa tanta bellea com en lo món trobar-se pogués. E sa fila Carmesina en moltes coses li era semblant, mas no generalment en totes, car aquesta en son temps l'excel.lia (Martorell, 1979: 755).

A aquest mateix capítol és l’emperadriu mateixa la qui s'imagina de la manera següent:

E puc dir ab veritat que jo estant en la piadosa vetla madormí, e prestament me donà de parer que estava en camisa ab una roba curta forrada de marts gebelins, de color de vellut verd... (Martorell, 1979: 759).

El detall final del passatge precedent mereix un breu comentari que creiem determinant per a la identificació del personatge de la novella amb el seu model històric. L’emperadriu Teodora fou acollida pels verds, una de les quatre faccions en què es dividien els participants a les conteses de l'hipòdrom, com el mateix Procopi ens explica:

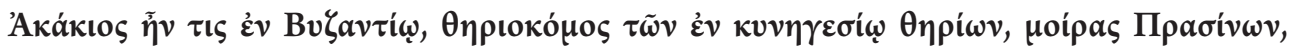

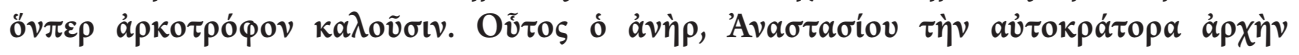

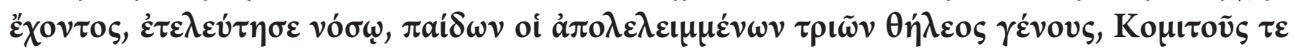

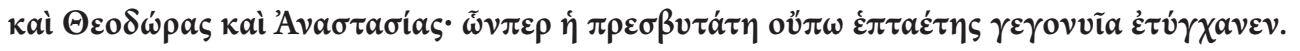

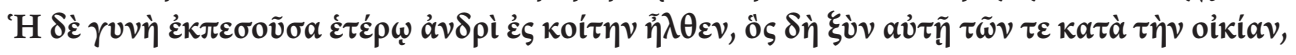

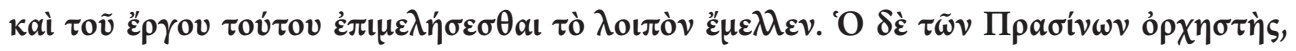

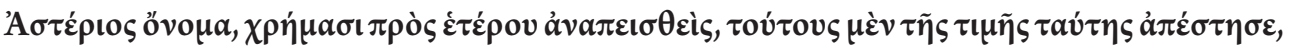

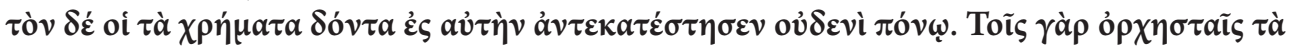

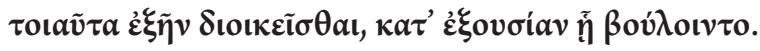

[Hi havia a Bizanci un tal Acaci, cuidador de les feres del clos de caça, del bàndol dels verds, que anomenen criador d'ossos. Aquest home al temps en què tenia el poder l'emperador Anastasi va morir d'una malaltia quedant-li tres fills de gènere femení, Comito, Teodora i Anastàsia, de les quals la més gran no arribava encara als disset anys. La dona es va ajuntar amb un altre home en braços del qual havia caigut, que a partir d'aquell moment havia 


\begin{abstract}
d'encarregar-se en companyia d'ella tant dels afers domèstics com d'aquella feina. Però el mestre de dansa dels verds, de nom Asteri, convençut amb diners per un altre, els va desposseir d'aquest càrrec i sense cap mena de penediment va posar al seu lloc per al càrrec el qui li va donar els diners. Als mestres de dansa els era permès d'administrar aquesta mena de càrrecs amb la discrecionalitat que vulguessin. (Procopi, Història secreta, IX, 1)]
\end{abstract}

No creiem, doncs, que l'al.lusió al vellut verd sigui casual, sempre que ens situem dins l'horitzó de la recepció de la llegenda de l’emperadriu Teodora, on la pertanyença a la facció dels verds figura entre els aspectes incontrovertibles. La identificació de l'emperadriu amb el color verd es fa de nou present al passatge següent, del capítol CCLXIV:

E venint la nit, que l'Emperador e tots los del palau sopaven, Hipòlit isqué del palau, e no anà a la posada de Tirant, sinó d'un mercader que es nomenava misser Bartolomeu Espicnardi, e féu-se aquí portar drap de brocat verd, e féu-se brodar les calces que la donzella l'havia pregat (Martorell, 1979: 767).

La nul.la consideració d'un capteniment digne per part dels amants, empedreïts practicants de llur mútua devoció, fa de tots dos uns personatges impúdics, sense cap de respecte envers els qui vertaderament havien honorat la passió de l’amor:

Llavors Hipòlit li volgué besar los peus e les mans. E l'Emperadriu no ho comportà, sinó que l'abraçà e besà estretament e passaren aquella delitosa nit molt poc recordants d'aquells que jaïen en los cadafals esperant que els fos feta l'honrada sepultura (Martorell, 1979: 1176; cap. CDLXXXI).

L'emperadriu, el mateix que Hipòlit respecte de Tirant, esdevé una contrafigura de Carmesina, on tot el que aquesta té de virtuosa el té aquella de desvergonyida pecadora. La temps era temps gran balladora, esdevinguda emperadriu i dona d'una bellesa sempre arravatadora i esclatant, definida com a malalta sexual per la seua obsessió per la bona companyia masculina, obtenia el màxim reconeixement, tant íntim com públic, als seus mèrits.

Si la nostra lectura literària, lingüística i històrica és correcta, l'autor o autors del Tirant lo Blanc varen triar, com una baula més dins l'arquitectura del seu pregon blasme de l'elit imperial bizantina, i en especial de la dinastia regnant, el personatge d'una emperadriu infidel, pèrfida, alienada per una malaltissa obsessió sexual. A la nostra lectura, l'etopeia de l'emperadriu Teodora, segles enrere construïda de manera duradora i influent per l'historiador Procopi, només té sentit a l’àmbit de la cultura bizantina i de la seua zona d'influència. És així, per exemple, com es registra l'eco literari d'una Teodora intransigent i artera, governada per la dolenteria i l'engany. Com diu El-Cheikh: «The negative tradition of Theodora is well-illustrated in a 12th century source in which she is described as unjust, perfidious and sly» (1997: 244; per a la font històrica, vegeu Al Tabari, 1991: 601). La base històrica d’aquesta Teodora traïdora fóra la notícia que l'emperadriu havia obligat uns presoners àrabs a convertir-se al cristianisme, o en el seu defecte ésser condemnats a mort.

Al Tirant, l'anònima emperadriu que sobreviu tant al seu fill com a la seua filla i a l'emperador, i que satisfà els seus desigs en casar-se amb el seu amant, la dona que malgrat la seua edat reuneix tots els atractius que pot abellir un home, seu al tron de Bizanci com una nova Teodora. 


\section{Bibliografia}

Al TABARI, Abu Ya’far Muhammad ibn Jarir (1991), Tárikh al-Umam wal Mulúk [Història dels profetes $i$ reis], Beirut, 10 vols. vol. II.

Alemany, Rafael (2002), «La diversitat polifónica del discurs amorós en el Tirant lo Blanc», Estudi General, 22, pp. 393-408.

Allen, Pauline (1992), «Contemporary Portrayals of the Empress Theodora (A.D. 527-548)», en Stereotypes of Women in Power, eds. B. Garlick et al., Londres i Nova York, Greenwood Press, pp. 93-103.

Beltran, Rafael (1989), «El personatge d'Eliseu (Tirant lo Blanc) a l'espill de Lucrecia (La Celestina): retrat de la donzella com a còmplice fidel de l'amor secret», en Miscelllània Joan Fuster: estudis de llengua i literatura, eds. A. Ferrando i A. G. Hauf, Barcelona, Publicacions de l'Abadia de Montserrat, pp. 95-124.

CACHo Blecua, Juan Manuel (1993), «El amor en el Tirant lo Blanc: Hipòlit y la Emperadriu», en Actes del Symposion Tirant lo Blanc, Barcelona, Quaderns Crema, pp. 133-169.

Cameron, Averil (1985), «Procopius and Theodora», dins el seu Procopius and the Sixth Century, Londres, Duckworth, pp. 52-83.

El-Cheikh, Nadia-Maria (1997), «Describing the Other to Get at the Self: Byzantine Women in Arabic Sources (8th-11th centuries) $\gg$, Journal of the Economic and Social History of the Orient, 40, pp. 239-250.

Evans, James Allan Steward (1984), «The 'Nika' Rebellion and the Empress Theodora», Byzantion, 54, pp. 380-382.

Finneran, Niall (2010), «Beyond Byzantium: the Non-Chalcedonian Church», en A Companion to Byzantium, ed. Liz James, Chichester/Malden, Wiley-Blackwell, pp. 199-223.

Fisher, Elizabeth A. (1973), «Theodora and Antonina in the Historia Arcana: History and/or Fiction?», Arethusa, 11, pp. 253-279.

GraU, Sergi i Oriol Febrer (2020), «Procopius on Theodora: ancient and new biographical patterns», Byzantinische Zeistschrift, 113, pp. 751-768.

Kotsis, Kriszta (2016), «Empress Theodora: A Holy Mother», en C. Fleiner \& E. Woodacre (edd.), Virtuous or Villainess? The Image of the Royal Mother from the Early Medieval to the Early Modern Era, Nova York, Palgrave Macmillan, pp. 11-36.

Leppin, Hartmut (2002), «Theodora und Iustinian», en Die Kaiserinnen Roms. Von Livia bis Theodora, ed. Hildegard Temporini-Gräfin Vitzthum, Munich, C.H. Beck, pp. 437-481.

Martorell, Joanot; Martí Joan de Galba (1982), Tirant lo Blanc i altres escrits de Joanot Martorell, Barcelona, Ariel.

Migne, Jacques Paul (1864), Patrologia Latina, CXvi, París.

PARKer, Margaret R. (1996), The Story of a Story Across Cultures: The Case of the «Doncella Teodor», Londres, Boydell \& Brewer.

Porcel Bueno, David (2015), «De nuevo sobre los modelos orientales de La historia de la donceIla Teodor $\gg$, en Literatura y ficción: 'estorias', aventura y poesía en la Edad Media, ed. Marta Haro Cortés, València, PUV, vol. i, pp. 423-436.

Scarborough, John (2013), «Theodora, Aetius of Amida, and Procopius: Some Possible Connections», Greek, Roman, and Byzantine Studies, 53, pp. 742-762.

Ziche, Hartmut G. (2012-2013), «Abusing Theodora: sexual and political discourse in Procopius», Byzantiaka, 30, pp. 311-323. 
